\title{
Terpolymerization of $\mathrm{CO}_{2}$ with Propylene Oxide and $\varepsilon$-Caprolactone using Zinc Glutarate Catalyst
}

\author{
Yongtaek Hwang, Jaehwan Jung, and Moonhor Ree* \\ School of Environmental Science and Engineering, Department of Chemistry, Center for \\ Integrated Molecular Systems, BK21 Program, Polymer Research Institute, and Division of \\ Molecular and Life Sciences, Pohang University of Science and Technology \\ San 31, Hyoja-dong, Pohang 790-784, Republic of Korea
}

\section{Heesoo Kim}

Department of Microbiology, Dongguk University College of Medicine, 707 Seokjang-dong, Gyeongju 780-714, Republic of Korea

Ms. No: ma034498b

\footnotetext{
* To whom all correspondence should be addressed.

Tel: +82-54-279-2120; Fax: +82-54-279-3399;

E-mail: ree@postech.edu
}

Revised on August 30, 2003

The revised parts are shaded by yeloow color. 


\begin{abstract}
The zinc glutarate ( $\mathrm{ZnGA}$ ) catalyzed terpolymerization of $\mathrm{CO}_{2}$ with propylene oxide (PO) and $\varepsilon$-caprolactone (CL) was achieved, producing poly(propylene carbonate- $c o-\varepsilon$-caprolactone)s with reasonably high molecular weight in high yields. PO and CL were used in the terpolymerization as both comonomers and reaction media and, after the reaction was complete, the excess comonomers were easily recovered and reused in the next terpolymerization batch. Therefore, the terpolymerization developed here is an environmentally friendly pollution-free synthetic process for aliphatic poly(carbonate-co-ester) terpolymers. The synthesized terpolymers exhibited excellent enzymatic and biological degradabilities.
\end{abstract}

Keywords: zinc glutarate catalyst, $\mathrm{CO}_{2}$ /oxirane/lactone terpolymerization, aliphatic carbonateester terpolymers, biodegradability 


\section{Introduction}

$\mathrm{CO}_{2}$ is considered the major greenhouse gas responsible for global warming, which may contribute to climate change. ${ }^{1}$ Thus, the reduction of $\mathrm{CO}_{2}$ emissions is a high priority, and $\mathrm{CO}_{2}$ capture and utilization (or disposal) are currently being actively investigated. In fact, $\mathrm{CO}_{2}$ is the cheapest and most abundant raw material source of carbon. One possible utilization of $\mathrm{CO}_{2}$ is in the production of polymeric materials that can be used in industry. A good example of such polymeric materials is poly(alkylene carbonate), which can be produced by the copolymerization of $\mathrm{CO}_{2}$ with oxirane. ${ }^{2-4}$ However, the major drawback of this approach is the relatively high stability of $\mathrm{CO}_{2}$, which means that its copolymerization with alkylene oxide requires a highly active catalyst. Among the various catalysts reported to date, zinc glutarate $(\mathrm{ZnGA})$, which is prepared from zinc oxide and glutaric acid, is thought to be the most effective catalyst for the production of poly(propylene carbonate) (PPC) with high molecular weight from $\mathrm{CO}_{2}$ and propylene oxide $(\mathrm{PO}){ }^{2-4}$ Recently, we reported a highly efficient process for the copolymerization of $\mathrm{CO}_{2}$ and PO using a ZnGA catalyst that can produce PPC in a high yield. ${ }^{4 a}$ In this new copolymerization process, $\mathrm{PO}$ is used both as a comonomer and as the reaction medium; thus no organic solvent is involved in the copolymerization and the process does not produce organic solvent waste. ${ }^{4 a}$ On the other hand, aliphatic polyesters are presently thought to be the most attractive class of artificial polymers from the environmental standpoint, in that they degrade in contact with living tissues and in outdoor conditions. ${ }^{5}$ In particular, poly $(\varepsilon$ caprolactone) (PCL) is biodegradable and of commercial interest because of its remarkable compatibility with a number of polymers. ${ }^{5}$

\section{Results and Discussion}


In the present study, we first successfully carried out the zinc glutarate-catalyzed terpolymerization of $\mathrm{CO}_{2}$ with $\mathrm{PO}$ and $\varepsilon$-caprolactone $(\mathrm{CL})$, producing aliphatic carbonate-ester terpolymers with the improved biodegradability that is essential for biomedical and environmental applications. The ZnGA catalyst used here was synthesized from zinc oxide and glutaric acid, as described elsewhere. ${ }^{4} \mathrm{PO}$ and $\mathrm{CL}$ were used as comonomers as well as reaction media, so no additional organic solvent was used in the terpolymerization, resulting in no organic solvent waste. The polymer products of this terpolymerization process were found to be highly soluble in $\mathrm{PO}$ and $\mathrm{CL}$, confirming the appropriateness of the use of $\mathrm{PO}$ and $\mathrm{CL}$ as both comonomers and reaction media. The use of an excess of PO and CL as the reaction solvent plays an important role in this terpolymerization because it ensures the efficient mixing of the reactants during the reaction. After the terpolymerization is complete, the excess amounts of $\mathrm{PO}$ and $\mathrm{CL}$ are easily recovered and reused in the next terpolymerization batch. The terpolymerizations of $\mathrm{CO}_{2}, \mathrm{PO}$ and $\mathrm{CL}$ in various compositions were conducted in an autoclave reactor at $60^{\circ} \mathrm{C}$ for $40 \mathrm{~h}$ (Scheme 1), where the reactor was pressurized to $400 \mathrm{psi}$ with $\mathrm{CO}_{2}$. The results of the terpolymerizations are summarized in Table 1.

As shown in Table 1, the polymer products were synthesized with reasonably highly molecular weights; their yields ranged from 0 to $59.8 \mathrm{~g}$ per gram of catalyst, depending on the molar feed ratio of PO and CL. In particular, the product yield decreased when the CL is loaded more than 50 mol-\% with respect to the total mole of PO and CL. Further, there was no homopolymerization of CL. This indicates that the ZnGA catalyst does not have any catalytic activity for the polymerization of CL monomer alone.

It is known that the copolymerization of $\mathrm{CO}_{2}$ and $\mathrm{PO}$ is accompanied by the formation of cyclic propylene carbonate as a byproduct. ${ }^{2,3,4 b}$ However, the characteristic chemical shifts of such cyclization byproducts were not detected in any of the nuclear magnetic resonance (NMR) 
spectra obtained from the terpolymerizations conducted in the present study. Further, for each terpolymerization, the total yield of polymer product that was insoluble in methanol was $>99 \%$. In contrast, methanol-soluble product, which contains ether-linkages on the polymer backbone, was obtained only in very small quantities.

The chemical compositions of the methanol-insoluble polymer products were characterized by proton $\left({ }^{1} \mathrm{H}\right)$ and carbon $\left({ }^{13} \mathrm{C}\right)$ NMR spectroscopy. Figure 1 shows representative NMR spectra, which were obtained from the polymer products obtained by the terpolymerization of $\mathrm{CO}_{2}$ with PO and CL with a 5:5 molar feed ratio. The NMR peaks were assigned as shown in Figure 1 and as summarized in Ref. 7. In the ${ }^{1} \mathrm{H}$ NMR spectrum, a number of additional weak peaks (marked by asterisks) also appear, while in the ${ }^{13} \mathrm{C}$ NMR spectrum each carbon peak appears with another weak peak nearby. To determine the origins of these weak peaks, two dimensional (2D) protoncarbon correlation NMR spectral analysis was performed. The asterisk-marked proton peaks, as well as the weak carbon peaks near those of the carbons $(F, G, H, I$, and $J)$, were found to originate from the CL units in the polymer backbone. These NMR results collectively lead to the conclusion that there exist two environmentally different $C L$ units in the polymer backbone, namely $\mathrm{CL}$ units directly linked to PC units (i.e. PC-linked $C L$ units), and blocked $C L$ units. The chemical compositions of all polymer products were estimated from the integrations of the assigned proton NMR peaks, including the asterisk-marked proton peaks. The results are listed in Table 2.

Glass transition temperature $\left(T_{g}\right)$ and melting point $\left(T_{m}\right)$ of the methanol-insoluble polymer products were measured by differential scanning calorimetry (DSC); the results are summarized in Table 1. The PPC polymer containing no CL units reveals only a single $T_{g}, 38.6^{\circ} \mathrm{C}$, indicating that the PPC polymer is amorphous. A PCL polymer $[70 \mathrm{k} \overline{M w}$ (weight-average molecular weight)], which was prepared by the homopolymerization of CL monomer in nitrobenzene using 
methyl triflate as a catalyst, is a crystalline polymer, thus showing $-63.2^{\circ} \mathrm{C} T_{g}$ and $57.9^{\circ} \mathrm{C} T_{m}$ (data not shown in Table 1). Taking these results and the determined compositions into account, PPCCL terpolymers are expected to reveal two $T_{g} \mathrm{~s}$ (one from the PC blocks and another from the CL blocks) and a single $T_{m}$ (from the CL blocks). All the terpolymers show a single $T_{m}$, which originates from the CL blocks, but only a single $T_{g}$, which originates from the PC blocks; another $T_{g}$ originated from the CL blocks could not be determined due to the very weak glass transition in the DSC measurements.

As seen in Table $1, \mathrm{ZnGA}$ exhibits good catalytic activity in the terpolymerization of $\mathrm{CO}_{2}$, $\mathrm{PO}$ and $\mathrm{CL}$, in addition to its activity in the copolymerization of $\mathrm{CO}_{2}$ and $\mathrm{PO}$, but no catalytic activity was observed in the homopolymerization of CL. Further, ZnGA has been reported to polymerize $\mathrm{PO}$ but not to initiate the polymerization of $\mathrm{CO}_{2}{ }^{2-4,7}$ In fact, $\mathrm{ZnGA}$ consists of an electrophilic zinc metal center and the nucleophilic carboxyl groups of the ligand. A ligand carboxyl group of $\mathrm{ZnGA}$ was detected at the end of a polycarbonate chain produced by the ZnGA-catalyzed polymerization of $\mathrm{CO}_{2}$ and $\mathrm{PO}^{2 \mathrm{2c}, 3 \mathrm{a}}$ Moreover, a recent near-edge X-ray absorption fine structure spectroscopy study of $\mathrm{ZnGA}$ found that the ZnGA reversibly reacts with $\mathrm{CO}_{2}$ and readily reacts with $\mathrm{PO}$ via adsorption onto the catalyst surface and insertion into the $\mathrm{Zn}$ $\mathrm{O}$ bond. $^{4 \mathrm{e}}$ These results collectively suggest that the $\mathrm{Zn}{ }^{\mathrm{II}}$ centers positioned at the surface function as active sites in the copolymerization of $\mathrm{CO}_{2}$ and PO. Taking these considerations into account, an anionic mechanism for the terpolymerization of $\mathrm{CO}_{2}$ with $\mathrm{PO}$ and $\mathrm{CL}$ is proposed here as follows. The nucleophilic oxygen atom of the PO monomer, which has a higher reactivity due to its high ring strain, is first drawn towards to the zinc metal center of the ZnGA catalyst and then is inserted into the zinc-carboxyl bond, activating the zinc mental center. In the next step, the two comonomers $\mathrm{CO}_{2}$ and $\mathrm{CL}$ competitively interact with the activated zinc metal center and are inserted into the growing chain. Then, $\mathrm{PO}, \mathrm{CO}_{2}$, and $\mathrm{CL}$ are all competitively added to the $\mathrm{ZnGA}$ 
catalyst and thus to the growing chain throughout the terpolymerization process. Taking into consideration the chemical compositions of the terpolymers as listed in Table 2, the addition of PO seems more favorable than that of $\mathrm{CL}$ immediately after $\mathrm{CO}_{2}$ insertion, while the addition of $\mathrm{CL}$ is more favorable than that of $\mathrm{CO}_{2}$ or PO immediately after CL insertion. This situation is due to the different reactivities of the comonomers and produces the formation of blocky PC and CL units in the growing polymer chain.

The terpolymers were treated with a lipase (Pseudomonas cepacia) in a phosphate buffer solution of $\mathrm{pH} 7.0$ at $37^{\circ} \mathrm{C}$ for 10 days, exhibiting $18 \sim 67 \%$ weight loss depending on the composition; larger content of the CL component in the terpolymer revealed larger weight loss in the enzymatic degradation. Figure 2 shows scanning electron microscopic images taken before and after enzymatic treatments of the terpolymer specimens; surface erosions due to the enzymatic degradations are clearly evident in the figure. In addition, terpolymers exhibited 10 15\% weight loss as a result of their treatment with Aspergillus fumigatus, Aspergillus terreus or Penicillium olonii in a phosphate buffer solution of $\mathrm{pH} 7.0$ at $25^{\circ} \mathrm{C}$ for 25 days. These enzymatic and biological degradabilities are comparable to those of the PCL homopolymer. In contrast, PPC itself exhibited only $9.5 \%$ weight loss in the enzymatic degradation, but no weight loss in the biological degradations. In conclusion, the terpolymers exhibited excellent enzymatic and biological degradability, suggesting their merit as candidate materials for biomedical applications.

Acknowledgement. This study was supported by the Center for Integrated Molecular Systems (KOSEF), by the Ministry of Education (BK21 Program), and by POSCO.

Supporting Information Available: 2D NMR data for a PPCCL terpolymer (PDF). This material is available free of charge via the Internet at http://pups.acs.org. 


\section{References and Notes}

(1) Paul, J.; Pradier, C. M., eds. Carbon Dioxide Chemistry: Environmental Issues, Royal Soc. Chem., Cambridge, 1994.

(2) (a) Inoue, S.; S.; Koinuma, H.; Tsuruta, T. Makromol. Chem. 1969, 130, 210. (b) Soga, K.; Imai, E.; Hattori, I. Polymer J. 1981, 13, 407. (c) Kuran, W.; Listos, T. Macromol. Chem. Phys. 1994, 195, 977.

(3) (a) Darensbourg, D. J.; Holtcamp, M. W. Coord. Chem. Rev. 1996, 153, 155. (b) Darensbourg, D. J.; Wildeson, J. R.; Yarbrough, J. C.; Reibenspies, J. H. J. Am. Chem. Soc.2000, 122, 12487. (c) Super, M.; Berluche, E.; Costello, C.; Beckman, E. Macromolecules 1997, 30, 368. (d) Tan, C.-S.; Hsu, T.-J. Macromolecules 1997, 30, 3147.

(e) Cheng, M.; Lobkovsky, E. B.; Coates, G. W. J. Am. Chem. Soc. 1998, 120, 11018. (f) Jung, J. H.; Ree, M.; Chang, T. J. Polym. Sci.: Polym. Chem. 1999, 37, 3329. (g) Archibald, S. J.; Foxon, S. P.; Freeman, J. D.; Hobson, J. E.; Perutz, R. N.; Walton, P. H. J. Chem. Soc. Dalton Trans. 2002, 2797.

(4) (a) Ree, M.; Bae, J. H.; Jung, J. H.; Shin, T. J. J. Polym. Sci.: Part A: Polym.Chem.1999, 37, 1863. (b) Ree, M.; Bae, J. H.; Jung, J. H.; Shin, T. J. Kor. Polymer J. 1999, 7, 333. (c) Ree, M.; Bae, J. Y.; Jung, J. H.; Shin, T. J.; Hwang, Y.-T.; Chang, T. Polym. Eng. Sci. 2000, 40, 1542. (d) Kim, J.-S.; Ree, M.; Shin, T. J.; Han, O. H.; Cho, S. J.; Hwang, Y.-T.; Bae, J. Y.; Lee, J. M.; Ryoo, R.; Kim, H. J. Catalysis 2003, 218, 209. (e) Kim, J.-S.; Ree, M.; Lee, S. W.; Hwang, Y.-T.; Baek, S.; Lee, B.; Shin, T. J.; Kim, H. C.; Kim, K. J.; Kim, B.; Luning, J. J. Catalysis 2003, 218, 386.

(5) (a) Arvanitoyannis, I. Rev. Macromol. Chem. Phys. 1999, C39, 205. (b) Scott, G.; Gilead, D. Degradable Polymer, Chapman, London, 1995. 
(6) ${ }^{1} \mathrm{H}$ NMR $\left(\delta, \mathrm{CDCl}_{3}\right), 5.0(1 \mathrm{H}, \mathrm{C} \underline{\mathrm{H}}(\mathrm{a})), 4.1-4.34\left(2 \mathrm{H}, \mathrm{C}_{2}(\mathrm{~b})\right), 1.3\left(3 \mathrm{H}, \underline{\mathrm{C}}_{3}(\mathrm{c})\right), 4.0(2 \mathrm{H}$, $\left.\mathrm{C}_{2}(\mathrm{~h})\right), 2.3\left(2 \mathrm{H}, \underline{\mathrm{C}}_{2}(\mathrm{~d})\right), 1.6-1.7\left(4 \mathrm{H}, \underline{\mathrm{C}}_{2}(\mathrm{~g})\right.$ and $\left.\underline{\mathrm{C}}_{2}(\mathrm{f})\right), 1.4\left(2 \mathrm{H}, \mathrm{C}_{2}(\mathrm{e})\right) ;{ }^{13} \mathrm{C} \mathrm{NMR}(\delta$,

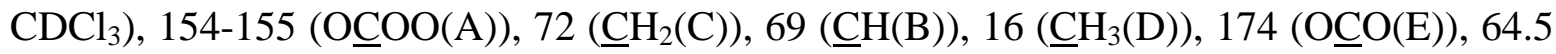
$\left(\mathrm{CH}_{2}(\mathrm{~J})\right), 34.5\left(\mathrm{CH}_{2}(\mathrm{~F})\right), 28.7\left(\underline{\mathrm{CH}}_{2}(\mathrm{I})\right), 25.9\left(\underline{\mathrm{CH}}_{2}(\mathrm{G})\right), 24.9\left(\underline{\mathrm{CH}}_{2}(\mathrm{H})\right)$.

(7) Lee, B.; Jung, J. H.; Ree, M. Macromol. Chem. Phys. 2000, 201, 831. 
Table 1. Terpolymerization of $\mathrm{CO}_{2}$, Propylene Oxide (PO), and $\varepsilon$-Caprolactone (CL) Using Zinc Glutarate Catalyst. ${ }^{\text {a }}$

\begin{tabular}{|c|c|c|c|c|c|}
\hline $\begin{array}{c}\mathrm{PO}: \mathrm{CL}^{\mathrm{b}} \\
\text { (molar ratio) }\end{array}$ & $\begin{array}{c}\mathrm{PO}: \mathrm{CL} \\
\quad(\mathrm{mL})\end{array}$ & $\begin{array}{l}\text { Yield }^{\mathrm{c}} \\
\text { (g/g cat.) }\end{array}$ & $\begin{array}{l}\text { Molecular weight } \\
\overline{M n} / \overline{M w} / \mathrm{PDI}^{\mathrm{d}}\end{array}$ & $\begin{array}{c}{[\eta]^{\mathrm{e}}} \\
(\mathrm{dL} / \mathrm{g})\end{array}$ & $\begin{array}{c}T_{g} / T_{m}{ }^{\mathrm{f}} \\
\left({ }^{\circ} \mathrm{C}\right)\end{array}$ \\
\hline $10 / 0$ & $100: 0$ & 50.3 & $226 \mathrm{k} / 673 \mathrm{k} / 2.97$ & 0.992 & $38.6 /-$ \\
\hline $7 / 3$ & $60: 40$ & 47.7 & $137 \mathrm{k} / 381 \mathrm{k} / 2.79$ & 0.903 & $17.7 / 51.0$ \\
\hline $6 / 4$ & $49: 51$ & 59.8 & $215 \mathrm{k} / 363 \mathrm{k} / 1.69$ & 0.921 & $16.6 / 52.5$ \\
\hline $5 / 5$ & $39: 61$ & 47.0 & $243 \mathrm{k} / 369 \mathrm{k} / 1.52$ & 0.936 & $17.6 / 51.1$ \\
\hline $4 / 6$ & $30: 60$ & 38.7 & $275 \mathrm{k} / 423 \mathrm{k} / 1.54$ & 0.988 & $19.2 / 50.6$ \\
\hline $3 / 7$ & $21: 79$ & 33.0 & $180 \mathrm{k} / 271 \mathrm{k} / 1.50$ & 0.877 & $5.9 / 52.1$ \\
\hline $2 / 8$ & $14: 86$ & 20.2 & $17 \mathrm{k} / 69 \mathrm{k} / 4.08$ & 0.674 & $5.4 / 57.2$ \\
\hline $0 / 10$ & $0: 100$ & 0 & $-g$ & $-g$ & $-g$ \\
\hline \multicolumn{6}{|c|}{$\begin{array}{l}\text { a Polymerization was conducted at } 60^{\circ} \mathrm{C} \text { under } 400 \text { psi }(27.2 \mathrm{~atm}) \mathrm{CO}_{2} \text { pressure using } 1.00 \mathrm{~g} \\
\text { of catalyst. } \\
\text { b Feed molar ratio. } \\
\text { c } \text { Yield of polymer product insoluble in methanol. } \\
\text { d } \text { Measured by gel permeation chromatography }(\mathrm{GPC}) \text { calibrated with polystyrene standards: } \\
\overline{M n} \text {, number-average molecular weight; } \overline{M w} \text {, weight-average molecular weight; PDI, } \\
\text { polydispersity. }\end{array}$} \\
\hline
\end{tabular}


Table 2. Composition of PPCCL Terpolymers. ${ }^{\text {a }}$

\begin{tabular}{cccc}
\hline PO:CL & \multicolumn{3}{c}{ Composition (molar fraction in \%) } \\
\cline { 2 - 4 } (feed molar ratio) $^{\mathrm{b}}$ & $\begin{array}{c}\text { PC } \\
\text { unit }\end{array}$ & $\begin{array}{c}\text { PC-linked } \\
\text { CL unit }\end{array}$ & $\begin{array}{c}\text { blocked } \\
\text { CL unit }\end{array}$ \\
\hline $7 / 3$ & 78.6 & 7.7 & 13.7 \\
$6 / 4$ & 61.4 & 5.7 & 32.9 \\
$5 / 5$ & 67.4 & 4.6 & 28.0 \\
$4 / 6$ & 68.9 & 12.2 & 18.9 \\
$3 / 7$ & 36.8 & 18.4 & 44.8 \\
2 / 8 & 17.8 & 17.7 & 64.5 \\
\hline
\end{tabular}

${ }^{\mathrm{a}}$ Feed mole ratio.

b Molar fractions of PPC and PCL units in the PPCCL product were determined by ${ }^{1} \mathrm{H}$ NMR spectroscopy. 


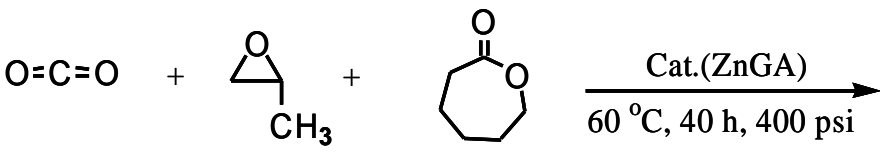

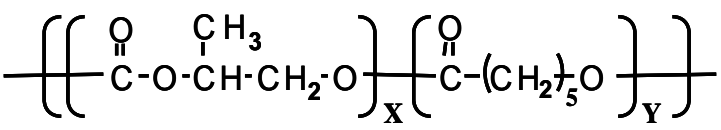

Scheme 1. Terpolymerization of carbon dioxide with propylene oxide and $\varepsilon$-caprolactone, producing poly(propylene carbonate-co- $\varepsilon$-caprolactone) (PPCCL). 

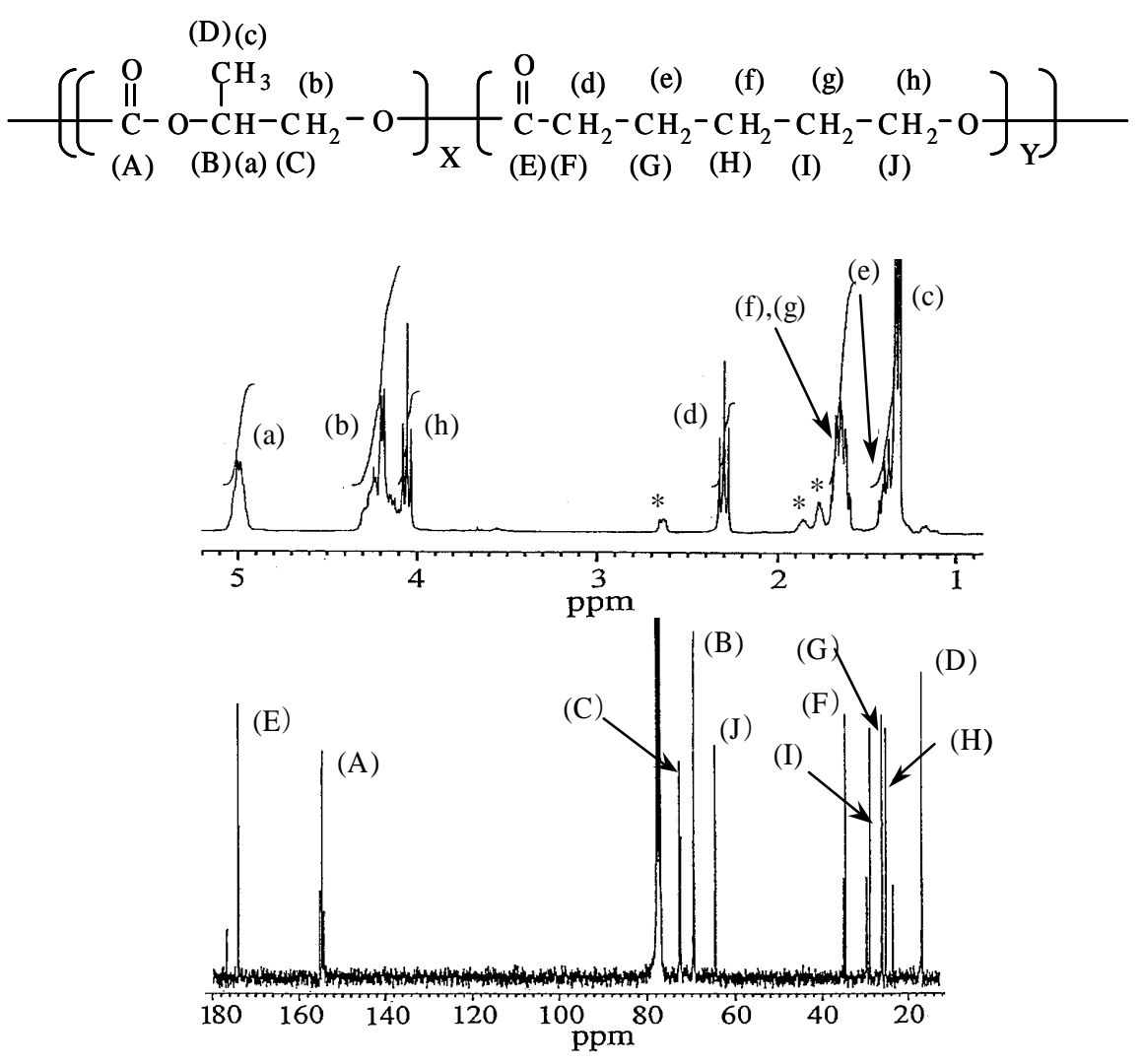

Figure 1. ${ }^{1} \mathrm{H}$ NMR (top) and ${ }^{13} \mathrm{C}$ NMR (bottom) spectra of a PPCCL terpolymer prepared by $\mathrm{CO}_{2}$ terpolymerization with $\mathrm{PO}$ and $\mathrm{CL}$ in 5:5 feed molar ratio. ${ }^{6}$ 


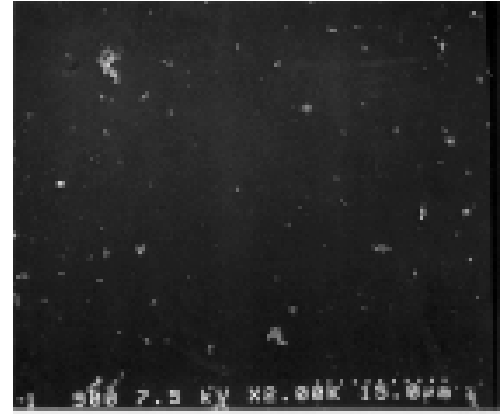

(a)

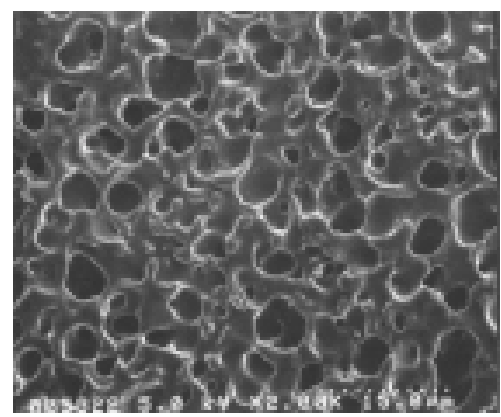

(c)

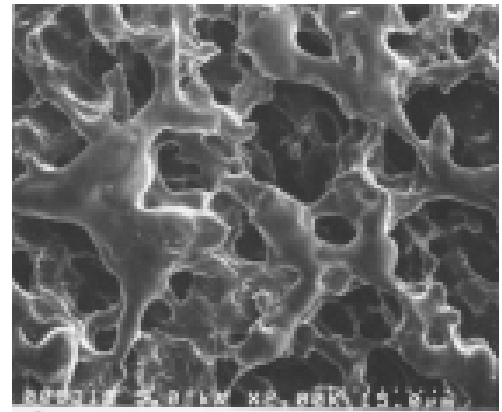

(b)

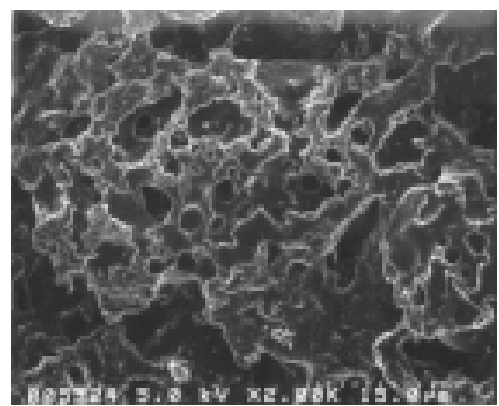

(d)

Figure 2. Scanning electron micrographs of the terpolymer films before and after enzymatic degradation with a lipase (Pseudomonas cepacia): (a) PPCCL (5/5 = P O/CL, feed mole ratio) before degradation; (b) PPCCL ( $7 / 3=$ PO/CL, feed mole ratio) after enzymatic degradation ( $18 \%$ weight loss); (c) PPCCL (5/5 = PO/CL, feed mole ratio) after enzymatic degradation (30\% weight loss); (d) PPCCL (3/7 = PO/CL, feed mole ratio) after enzymatic degradation (67\% weight loss). 